\title{
Tandem Affinity Depletion: A Combination of Affinity Fractionation and Immunoaffinity Depletion Allows the Detection of Low-Abundance Components in the Complex Proteomes of Body Fluids
}

\author{
Naghmeh Mortezai, ${ }^{\dagger}$ Sönke Harder, ${ }^{\dagger}$ Claudia Schnabel, ${ }^{\dagger}$ Eva Moors, ${ }^{\ddagger}$ Matthias Gauly, ${ }^{\ddagger}$ \\ Hartmut Schlüter, ${ }^{\dagger}$ Christoph Wagener, ${ }^{\dagger}$ and Friedrich Buck ${ }^{*, \dagger}$ \\ Institute of Clinical Chemistry, University Medical Center Hamburg-Eppendorf, \\ Martinistr. 52, D-20246 Hamburg, Germany, and Department of Animal Science, University of Göttingen, \\ Albrecht-Thaer-Weg 3, D-37075 Göttingen, Germany
}

Received March 11, 2010

\begin{abstract}
Protein biomarker discovery in the low concentration range of human body fluids requires the enrichment of the proteins of interest. Here we report on a tandem affinity strategy: In the first step, we isolated a human plasma glyco-subproteome of healthy individuals by wheat germ agglutinin (WGA) lectin affinity chromatography. In the second step, the proteins of this subproteome were used to raise antibodies in llama (Lama glama). The heavy-chain fraction of the llama antibodies was used to deplete from the WGA lectin binding fraction all proteins normally found in human plasma. In this way, we selectively enriched the glycoprotein, CEA, a known cancer marker which had been spiked into normal plasma. As a proof of concept, we applied this method to the analysis of plasma sample from colon cancer patients. We could demonstrate the selective enrichment of CEA by a factor of $600-800$.
\end{abstract}

Keywords: plasma proteomics • biomarker • glycoproteins • lectin affinity chromatography • wheat germ agglutinin • immunoaffinity depletion - Ilama heavy-chain antibody $\bullet \mathrm{MS}^{\mathrm{E}}$ mass spectrometry

\section{Introduction}

Pathological states often lead to small but characteristic changes in the proteome of body fluids as the result of differential gene activity, translation, degradation and protein modification. ${ }^{1,2}$ The identification and quantification of these changes can potentially be helpful in early diagnosis of a disease and monitoring of a therapy. Therefore, considerable efforts have been made in the last years to identify new diseaserelated proteins, in addition to the comparatively small number of established protein markers, for example, the cancer markers PSA, CA-125, and CEA. ${ }^{3}$ However, the identification and validation of sensitive and specific marker proteins is still a formidable task, ${ }^{4}$ due to the enormous complexity of human proteomes, ${ }^{4,5}$ the biological heterogeneity of the samples (both due to genetic diversity and differences in sex, age and lifestyle of the patients), and the difficulty to process large numbers of samples in a reproducible way. ${ }^{6-9}$ The detection of minor protein components in the presence of a large excess of other proteins poses a particular problem, both with respect to the total amount of protein analyzed (only a limited amount of material can be loaded onto a gel or a HPLC column) and to the quantity of a certain protein relative to other proteins in the sample (a given amount of protein, though detectable by itself, can be obscured in the presence of an excess of com-

\footnotetext{
* To whom correspondence should be addressed. E-mail: buck@uke.de.

† University Medical Center Hamburg-Eppendorf.

‡ University of Göttingen.
}

peting material, e.g. due to ion suppression in mass spectrometry). ${ }^{10}$ Because of these limitations, the dynamic range of analytical methods (including most mass spectrometric techniques) is $10^{4}$ at best, while protein concentrations in body fluids can differ by $>10^{11}$, for example, in the plasma proteome. ${ }^{4}$ Therefore, for the detection of minor components, fractionation is always required. ${ }^{11-13}$

Numerous fractionation techniques have been applied to reduce the complexity of the samples. ${ }^{14}$ For tissue and cellular material, subcellular components (e.g., nuclei) can be isolated or differential solubility can be used for fractionation (e.g., cytoplasmic proteins vs membranes). Subproteomes of body fluids can be separated based on physical properties (protein charge or size (e.g., GeLC-MS ${ }^{13}$ )) or on post-translational modifications (phosphoproteome, ${ }^{15}$ glycoproteomes ${ }^{16,17}$ ). Given that the majority of previously discovered disease specific proteins are glycosylated, ${ }^{18-24}$ the glycoproteome of the plasma can be seen as a particularly promising subproteome for the discovery of new disease-specific proteins.

Protein glycosylation provides a basis for various proteome fractionation strategies, either for the isolation of the total glycoproteome $\mathrm{e}^{25-27}$ or for the isolation of proteins carrying a specific glycostructure. ${ }^{28-30}$ However, even these subproteomes usually contain a number of highly abundant proteins, which limits the depth of analysis.

An alternative approach is the depletion by immunoaffinity techniques using antibodies directed against the most abundant proteins. ${ }^{31-33}$ Immunoaffinity columns for the depletion 
of 6,20 , or even more abundant proteins in human plasma are commercially available. A review of the various affinity prefractionation techniques is given by Pernemalm and colleagues. $^{35}$

In the present paper, we provide the proof of principle for a tandem depletion strategy, which combines the enrichment of a specific glyco-subproteome of human plasma (thereby depleting proteins not carrying that particular glycostructure) with an immunodepletion step using antibodies raised against all proteins of this subproteome found in healthy humans, thus dramatically enriching disease specific proteins within the respective subproteome. For the immunodepletion antibodies raised in llama were used. ${ }^{36}$ Sera from old world camels and llamas contain, in addition to conventional antibodies, a unique kind of antibodies formed by heavy chains only. ${ }^{36,37}$ In comparison to conventional antibodies, the heavy chain antibodies have several advantages for biotechnological applications: ${ }^{38}$ they have a higher stability with respect to $\mathrm{pH}$ and temperature; ${ }^{39,40}$ are well suited for selection systems such as phage display and can be expressed in microorganisms. ${ }^{38}$

For the identification and label-free quantification of the proteins isolated by this strategy electrospray QTOF LC-MS mass spectrometry was applied, using the data-independent $\mathrm{MS}^{\mathrm{E}}$ technique. ${ }^{41,42}$

\section{Experimental Section}

Production of Llama Antibodies. A llama (Lama glama) was immunized by the injection of a mixture of $0.5 \mathrm{~mL}(2 \mathrm{mg} / \mathrm{mL})$ WGA-bPP (proteins isolated from a plasma pool of healthy individuals by WGA affinity chromatography) and $0.625 \mathrm{~mL}$ adjuvant (Stimmune, Cedi Diagnostics B.V.). Three weeks before each blood withdrawal the animal was boosted as described above. The blood samples were centrifuged for 10 min at $2500 \mathrm{rpm}$ to separate the cellular components from the serum. The lama antiserum was stored at $-20{ }^{\circ} \mathrm{C}$.

The antibody titer of the llama serum was monitored by an ELISA. In the wells of a microtiter plate (MaxiSorp Nunc Immuno Moldule, Nunc), $100 \mu \mathrm{L}$ of $0.004 \mu \mathrm{g} / \mu \mathrm{L}$ WGA-bPP were pipetted for seven repeat determinations and eight blank values. The microtiter plate was incubated overnight at $4{ }^{\circ} \mathrm{C}$, washed three times with $200 \mu \mathrm{L}$ TBST (150 mM NaCl, $0.1 \mathrm{M}$ Tris-HCl pH 8, 2.5\% Tween 20), blocked with $200 \mu \mathrm{L}$ of 3\% BSA (dissolved in PBS) (Carl Roth, Karlsruhe, Germany) for $2 \mathrm{~h}$ at ambient temperature, and again washed three times with TBST. Each well was incubated with $100 \mu \mathrm{L}$ of $0.01 \mu \mathrm{g} / \mu \mathrm{L}$ llama serum in PBS for $1 \mathrm{~h}$ at ambient temperature and washed three times with $200 \mu \mathrm{L}$ of TBST. In each well, $100 \mu \mathrm{L}$ of a 1:30 000 goat anti llama IgG $(\mathrm{h}+\mathrm{l})$ Antibody HRP conjugated solution (BETHYL Laboratories, Montgomery, TX) was added and incubated for $1 \mathrm{~h}$ at ambient temperature, washed three times with 200 $\mu \mathrm{L}$ TBST, and $200 \mu \mathrm{L}$ of ABTS solution (PCR ELISA DIG Detection, Roche, NJ) were added. The microtiter plate was incubated for $30 \mathrm{~min}$ in the dark, and the absorbance at 405 $\mathrm{nm}$ was measured in an ELISA reader.

Llama Antibody Fractionation. Llama serum was fractionated into heavy chain and conventional IgG based on their different affinities to protein $G$ and protein A, respectively. Protein $\mathrm{G}$ and protein A Sepharose 4 Fast Flow ${ }^{\mathrm{TM}}$ were obtained from GE Healthcare, Munich, Germany and the chromatography done as described by Hamers-Castermann et al. ${ }^{43}$ Two $\mathrm{mL}$ of llama serum were thawed on ice, centrifuged (10 $\mathrm{min}$ at $10000 \mathrm{rpm})$, filtered $(0.22 \mu \mathrm{m}$ centrifugal unit (Spin-X, Omnilab)), diluted with an equal volume of PBS, loaded onto 5
$\mathrm{mL}$ protein $\mathrm{G}$ sepharose and incubated for $2 \mathrm{~h}$ at ambient temperature. The column was then washed with PBS until the $\mathrm{A}_{280}$ was $<0.01$. The bound antibodies were then eluted in two steps at pH 3.5 and $\mathrm{pH} 2.7$ as described by Hamers-Castermann $^{43}$ (details given in Supporting Information).

Llama Antibody Immobilization. For the immobilization of llama heavy chain antibodies four different commercially available matrices were tested: $\mathrm{CNBr}$ activated and NHS activated Sepharose 4B (GE Healthcare), a hydrazide matrix (CarboLink Coupling Gel, Pierce), and a protein G matrix (Seize X Protein G Immunoprecipitation Kit, Pierce). Coupling was done according to the manufacturers protocols.

HPLC Techniques. All HPLC runs were done on an ÄKTA Explorer FPLC (GE Healthcare) under the control of the software package UNICORNTM 4.00. Before each HPLC run the column was washed with a 3 -fold column volume of water and equilibrated with a 3 -fold column volume of the respective binding buffer. Samples were injected through a $50 \mathrm{~mL}$ superloop (GE Healthcare) at a flow rate $0.5 \mathrm{~mL} / \mathrm{min}$. During every HPLC run the conductivity, the pressure $\left(p_{\max }=0.5 \mathrm{MPa}\right)$ and the UV absorbance at $280 \mathrm{~nm}, 260$ and $220 \mathrm{~nm}$ were monitored. After each run the columns were rinsed with LiChrosolv water and stored in 20\% ethanol (Merck, Darmstadt) at $4{ }^{\circ} \mathrm{C}$. All solvents were HPLC grade (LiChroSolv, Merck, Darmstadt, Germany).

Wheat Germ Agglutinin (WGA) Lectin Affinity Chromatography. One milliliter of pooled human heparin plasma (DGH, Koblenz, Germany) of healthy donors (61 mg total protein) was centrifuged at $10000 \mathrm{rpm}$ and filtered through a $0.22 \mu \mathrm{m}$ spin centrifugal unit (Omnilab, Bremen, Germany), diluted 1:10 with WGA binding buffer (0.2 M Tris- $\mathrm{HCl} \mathrm{pH} \mathrm{7.5,} \mathrm{0.1} \mathrm{M} \mathrm{NaCl,} 1 \mathrm{mM}$ EDTA) and loaded onto the lectin column (7 mL WGA agarose, $4.8 \mathrm{mg}$ lectin $/ \mathrm{mL}$, (Sigma Aldrich) in a C 10/10-column (GE Healthcare)). The column was washed with $100 \mathrm{~mL}$ WGA binding buffer (flow rate $0.3 \mathrm{~mL} / \mathrm{min}$ ) and the lectin bound proteins eluted with $10 \mathrm{~mL}$ elution buffer $(0.2 \mathrm{M}$ Tris- $\mathrm{HCl} \mathrm{pH}$ 7.5, 0.1 M NaCl, $1 \mathrm{mM}$ EDTA with $0.5 \mathrm{M}$ GlcNAc (Sigma Aldrich)). The eluted glycoproteins were collected into LoBind tubes (Eppendorf, Hamburg, Germany). After each run, the column was rinsed with WGA binding buffer $(>100 \mathrm{~mL})$ until complete removal of the GlcNAc.

Immunoaffinity Chromatography (IAC). WGA-bPP (2.4 mg) in $10 \mathrm{~mL}$ PBS was loaded on a $60 \mathrm{~mL}$ immunoaffinity column (3 mg IgG3/mL antibody immobilized on hydrazide agarose as described above). The flow-through of the IAC was collected in $2 \mathrm{~mL}$ LoBind tubes (Eppendorf, Hamburg, Germany). The antibody column was washed with PBS until $\mathrm{A}_{280}<0.01$. The bound protein was eluted with $50 \mathrm{~mL} 0.1 \mathrm{M}$ glycine- $\mathrm{HCl} \mathrm{pH}$ 1.4. The column was neutralized with $100 \mathrm{~mL} 0.2 \mathrm{M}$ Tris- $\mathrm{HCl}$ pH 8.5 and washed with $180 \mathrm{~mL}$ PBS.

Size Exclusion Chromatography (SEC). For SEC experiments a HiPrepTM 26/10 column (GE Healthcare) was used (sample volume: $10 \mathrm{~mL}$, flow rate $0.3 \mathrm{~mL} / \mathrm{min}$, elution buffer: PBS (before first IAC, in order to transfer the sample into PBS) or $50 \mathrm{mM} \mathrm{NH}_{4} \mathrm{HCO}_{3}$ (after the second IAC, to transfer the sample into the tryptic digestion buffer)). Protein elution was monitored at $\mathrm{A}_{280}$.

Protein Analytical Techniques. Protein concentration: total protein concentrations were determined with a Bradford assay kit (Pierce).

Western Blotting: Proteins were transferred onto PVDF membranes (Immobilon P, Millipore) by semidry-blotting (Pegasus S, phase, Lübeck, Germany); blotting conditions: 10\% 
methanol, $150 \mathrm{mM}$ glycine, $25 \mathrm{mM}$ Tris $\mathrm{pH} 8.3$ for $1 \mathrm{~h}$ at 300 $\mathrm{mA})$. After transfer of the proteins the membrane was blocked with 3\% BSA (Carl Roth, Karlsruhe) in TBST (0.25\% Tween, 150 $\mathrm{mM} \mathrm{NaCl}, 10 \mathrm{mM}$ Tris-HCl pH 8) for $16 \mathrm{~h}$ at $4{ }^{\circ} \mathrm{C}$. The membrane was hybridized with $1 \mathrm{~mL}$ of the primary antibody solution $(0.3 \mu \mathrm{g} / \mu \mathrm{L})$ for $1 \mathrm{~h}$ at ambient temperature. For the CEA assay the membrane was hybridized with the monoclonal mouse antibody T84.1. ${ }^{44}$ The membrane was washed six times for $10 \mathrm{~min}$ with TBST and then incubated with the secondary antibody for $1 \mathrm{~h}$ at ambient temperature. Llama antibodies were detected with goat anti llama IgG $(\mathrm{h}+\mathrm{l}) \mathrm{HRP}$ conjugated antibody (1: 50 000, BETHYL Laboratories, Montgomery, TX). Mouse T84.1 antibody was detected with rabbit anti mouse HRP conjugated antibody (1: 25000 ). The membrane was washed six times for 10 min with TBST and incubated for 1 min with ECL solution (GE Healthcare). The chemoluminescence was detected on an Amersham Hyperfilm (GE Healthcare).

Immunodiffusion Assay: Plasma protease C1 inhibitor concentrations were determined by the method of radial immunodiffusion on NOR Partigen OUEI (Dade Behring, Germany) plates. Five microliters of undiluted plasma was transferred into the sample holes of the plates. After $48 \mathrm{~h}$ incubation at ambient temperature the diameter of the immunoprecipitation ring was measured and compared with reference values.

Mass Spectrometry. Sample preparation: Protein samples in $50 \mathrm{mM} \mathrm{NH} \mathrm{NHCO}_{3}$ containing $0.1 \%$ Rapigest surfactant (Waters) were incubated at $80{ }^{\circ} \mathrm{C}$ for $10 \mathrm{~min}$. To achieve complete denaturation of the proteins, DTT was added (final concentration $5 \mathrm{mM}$ ) and incubated at $60{ }^{\circ} \mathrm{C}$ for $10 \mathrm{~min}$, iodacetamide was added (final concentration $15 \mathrm{mM}$ ), incubated at ambient temperature for $30 \mathrm{~min}$ in the dark, trypsin (modified, sequencing grade, Promega) was added (final concentration $5 \mathrm{ng} / \mathrm{mL}$ ) and incubated at $37^{\circ} \mathrm{C}$ overnight. Finally, the $\mathrm{pH}$ of the samples was lowered to $<2$ by the addition $\mathrm{HCl}_{\text {conc }}$ to decompose the acid-labile Rapigest surfactant. The samples were centrifuged at maximal speed in an Eppendorf centrifuge and $1-3 \mu \mathrm{L}$ of the digest used for an LC-MS run.

LC-MS runs were done on a QTOF Premier tandem mass spectrometer (Waters-Micromass) equipped with an Aquity UPLC (Waters). Samples were applied onto a trapping column (Waters nanoAquity UPLC column, C18, $180 \mu \mathrm{m} \times 20 \mathrm{~mm}$ ), washed for $10 \mathrm{~min}$ with $5 \%$ acetonitrile, $0.1 \%$ formic acid (5 $\mu \mathrm{L} / \mathrm{min}$ ) and then eluted onto the separation column (Waters nanoAquity UPLC column, C18, $100 \mu \mathrm{m} \times 100 \mathrm{~mm}, 400 \mathrm{~nL} /$ min) with a gradient (A, $0.1 \%$ formic acid; B, $0.1 \%$ formic acid in acetonitrile, 5-50\% $\mathrm{B}$ in $120 \mathrm{~min}$ ). The spray was done from a stainless steel emitter (I.D. $30 \mu \mathrm{m}$, Proxion, Odense) at a capillary voltage of $2.6 \mathrm{kV}$. To identify and labelfree quantify the proteins, the $\mathrm{MS}^{\mathrm{E}}$ technique ${ }^{41,42}$ was applied: alternating scans $(0.95 \mathrm{~s}, 0.05 \mathrm{~s}$ interscan delay) with low $(4 \mathrm{eV})$ and high (ramp from 20-35 eV) collision energy were recorded. The data were evaluated with the software package Protein Lynx Global Server version 2.3 (Waters). At intervals of $10 \mathrm{~s}$ a lockspray spectrum (1 pMol $/ \mu \mathrm{L}\left[\mathrm{Glu}^{1}\right]$ Fibrinopeptide B (Sigma)) was recorded. Using lockspray correction a mass accuracy of \pm 7 ppm was achieved in the MS mode. As a quantification standard a tryptic digest of yeast enolase (Waters) to a final concentration of $100 \mathrm{fmol} / \mu \mathrm{L}$ was added to each sample.

\section{Results and Discussion}

a. Lectin Affinity Purification. Lectin affinity purification on immobilized wheat germ agglutinin (WGA) was used for the isolation and fractionation of the human plasma glycoproteome. WGA recognizes $\mathrm{N}$-acetyl-glucosamine (GlcNAc) and also has an affinity to sialic acid. ${ }^{16,45-47}$ Under the experimental conditions, $4.0 \pm 0.1 \%$ ( $2.4 \mathrm{mg}$ of $61 \mathrm{mg}$ ) of the total plasma protein from healthy humans was bound to immobilized WGA and eluted by GlcNAc. Comparison of the WGA-bPP with unfractionated plasma by $\mathrm{LC}-\mathrm{MS} / \mathrm{MS}^{\mathrm{E}}$ revealed the enrichment of numerous glycoproteins, but also the presence of residual albumin $(1.5-2 \%$ of the total albumin, data not shown), either due to nonspecific binding to the matrix or by complex formation with bound glycoproteins.

b. Antibody Purification. The serum obtained from a llama immunized with WGA-bPP was fractionated by affinity chromatography on immobilized protein $\mathrm{G}$ and subsequently on protein A. ${ }^{48}$ The purification was monitored by SDS gel electrophoresis (data not shown).

The binding strength of the antibody fractions was tested in a Western blot assay using WGA-bPP as antigen. The protein pattern recognized by the various subtypes of heavy chain antibodies (IgG2a, IgG2b, IgG3) did not differ significantly from that of the conventional antibodies (IgG1) (see Supp. Materials for details). For all further experiments the heavy chain antibody fraction IgG3 was used.

c. Antibody Immobilization. Four procedures of protein immobilization were tested for the immobilization of llama IgG3 heavy chain antibodies. Immobilization yields through cross-linking to protein $\mathrm{G}$ sepharose were low ( $7.5 \%)$, while immobilization through amino groups to $\mathrm{CNBr}$ sepharose and NHS sepharose or through oxidized carbohydrate residues to hydrazide agarose all gave coupling yields of $\sim 84 \%$. Antigen binding capacities under assay conditions (50 $\mu \mathrm{g}$ WGA-bPP per $1 \mathrm{~mL}$ antigen matrix giving a 20 -fold excess of antigen over immobilized antibody) were comparable for the amino group based cross-linking techniques $(\sim 92 \%)$, while the binding capacity of the hydrazide immobilized antibody resin was slightly, but significantly higher ( 96\%) (for details see Suppl. Material). In order to determine, how many times the columns could be recycled, the experiment was repeated and each time the binding capacity as well as the loss of immobilized antibody were tested. For the CNBr immobilized antibody column, increasing amounts of llama antibody were detected by SDSPAGE and Western blot analysis (data not shown) in the flowthrough after $>15$ runs, while for the NHS or hydrazide coupled antibody columns after 40 runs no decrease in antigen binding capacity and no leakage of immobilized antibody was detected. Taken together, the immobilization by coupling to hydrazide agarose gave the best results. In all further experiments llama IgG3 heavy chain antibodies coupled to agarose by a hydrazideglycan link were used. For this resin the optimal antigen binding conditions with regard to $\mathrm{pH}$ (Table la), temperature and incubation time (Table 1b) were determined. As a conclusion from these experiments, all further experiments were done in PBS pH 7.2 at ambient temperature with an incubation time of $2 \mathrm{~h}$ for the binding of the antigen solution to the immobilized heavy chain IgG3 llama antibody.

d. Binding Specificity of the Llama IgG3 Heavy Chain Antibody Immunoabsorbens. The strategy described here requires the binding of high and medium abundant glycoproteins of the human plasma, while proteins not normally contained or significantly increased relative to normal in human plasma should be found in the flow-through of the column. In order to test this hypothesis we spiked samples of WGA-bPP with the known colon cancer marker carcinoembry- 
Table 1. Antigen Binding of the Immunoaffinity Column (1 mL slurry) at Different pH Values, Incubation Times, and Temperatures

\begin{tabular}{|c|c|c|c|c|c|c|}
\hline \multicolumn{7}{|c|}{ a. Antigen binding of the immunoaffinity column ( $1 \mathrm{~mL}$ slurry) at different $\mathrm{pH}$ values $\left(2 \mathrm{~h}\right.$ incubation at $\left.21{ }^{\circ} \mathrm{C}\right)$} \\
\hline buffer & $10 \mathrm{mM}$ PBS & $100 \mathrm{mM}$ Tris-HCl & $100 \mathrm{mM}$ Tris-HCl & $50 \mathrm{mM} \mathrm{NH}_{4} \mathrm{HCO}_{3}$ & & \\
\hline $\mathrm{pH}$ & 7.2 & 8.0 & 9.0 & 8.3 & & \\
\hline input $[\mu \mathrm{g}]$ & 50 & 50 & 50 & 50 & & \\
\hline flow through $[\mu \mathrm{g}]$ & $1.90 \pm 0.46$ & $5.20 \pm 0.42$ & $6.63 \pm 0.32$ & $6.07 \pm 0.23$ & & \\
\hline flow through [\%] & $3.8 \pm 0.92$ & $10.4 \pm 0.84$ & $13.26 \pm 0.64$ & $12.14 \pm 0.46$ & & \\
\hline \multicolumn{7}{|c|}{ b. Antigen binding of the immunoaffinity column ( $1 \mathrm{~mL}$ slurry) at different incubation times and temperatures (in $10 \mathrm{mM}$ PBS $\mathrm{pH} 7.2)$} \\
\hline temperature $\left[{ }^{\circ} \mathrm{C}\right]$ & 4 & 4 & 21 & 21 & 21 & 21 \\
\hline time $[\mathrm{h}]$ & 16 & 3 & 16 & 3 & 2 & 1 \\
\hline input $[\mu \mathrm{g}]$ & 50 & 50 & 50 & 50 & 50 & 50 \\
\hline flow through $[\mu \mathrm{g}]$ & $3.03 \pm 0.47$ & $4.13 \pm 0.51$ & $3.20 \pm 0.56$ & $3.07 \pm 0.25$ & $3.40 \pm 0.17$ & $4.27 \pm 0.49$ \\
\hline flow through [\%] & $6.06 \pm 0.94$ & $8.26 \pm 1.02$ & $6.4 \pm 1.12$ & $6.14 \pm 0.50$ & $6.80 \pm 0.34$ & $8.54 \pm 0.98$ \\
\hline
\end{tabular}

onic antigen (CEA from human fluids, Sigma-Aldrich). $50 \mu \mathrm{g}$ WGA-bPP was spiked with $1 \mu \mathrm{g}$ CEA and run over an immunoaffinity column ( $4 \mathrm{~mL}$ immunoaffinity resin loaded with 4 mg IgG3 heavy chain llama antibody). The CEA content of the flow-through and of the bound fraction was assayed by Western blot analysis after protein precipitation (Figure 1a). No significant binding of CEA to the immunoaffinity column was detected. The protein depletion of the sample was demonstrated by SDS gel electrophoresis of an identical sample without added CEA (Figure 1b). Both colloidal Coomassie and silver staining revealed only a single detectable band in the flow-through. The band was cut out, and the protein was identified by nanospray ESI mass spectrometry as $\alpha_{1}$-acidic glycoprotein 1 . e. Analysis of Spiked Plasma. The complete workflow of an analysis (Table 2) was tested with a plasma pool from healthy controls ( $1 \mathrm{~mL}$ containing $61 \mathrm{mg}$ protein) spiked with $3620 \mathrm{ng}$ (20 pM) CEA (from human fluids, Sigma-Aldrich). The sample was fractionated by WGA lectin affinity chromatography, the bound fraction was eluted by a $0.5 \mathrm{M}$ solution of GlcNAc, the GlcNAc was removed and the sample was transferred into PBS by gel filtration (SEC) and applied to the immunoaffinity column (60 $\mathrm{mL}$ resin, $3 \mathrm{mg} I g \mathrm{G} 3 / \mathrm{mL}$ ). The elution profile is shown in Figure 2. The removal of the GlcNAc and the exchange of the buffer were necessary, because the antigen binding of the immobilized antibodies was optimal in PBS buffer at pH 7.2 (see Table 1a). The depletion step by binding to the immunoaffinity column was repeated once. The CEA (a)

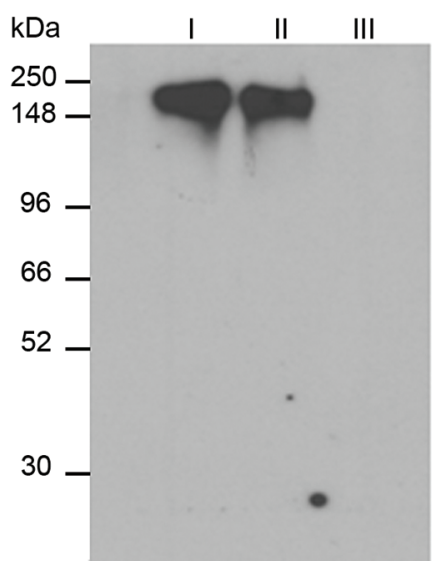

(b)

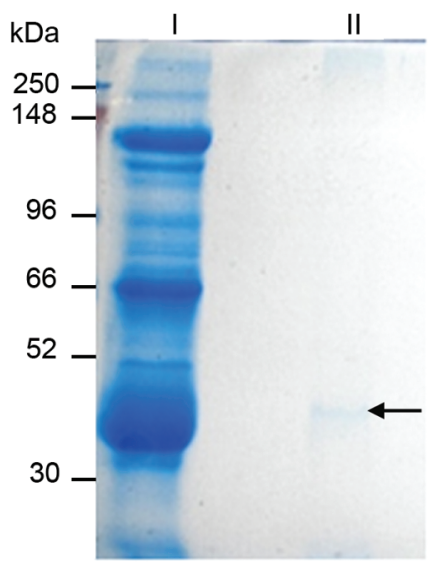

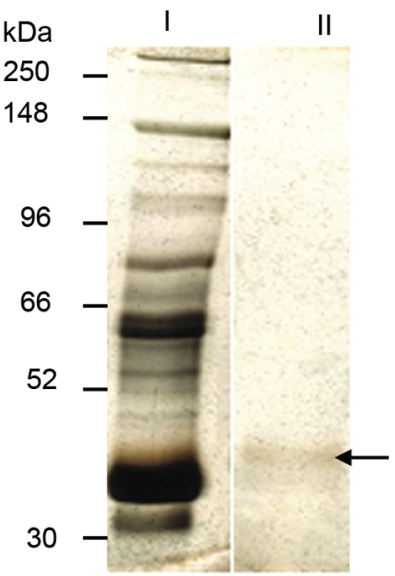

Figure 1. I: input, II: flow through, III: immunoaffinity bound fraction. (a) Western blot analysis of WGA-bPP spiked with CEA detected by hybridization with an anti-CEA antibody (T.84.1). (b) SDS gel electrophoresis (left, Coomassie stained; right, silver stained) demonstrating the protein depletion under the experimental conditions. The band in the flow through at $35 \mathrm{kD}$ (arrow) was identified as $\alpha_{1}$-acid glycoprotein.

Table 2. Sample Preparation of a Normal Plasma Sample Spiked with CEA

\begin{tabular}{|c|c|c|c|c|}
\hline & protein $[\mu \mathrm{g}]$ & CEA [ng] & ratio $_{\mathrm{CEA} / \text { plasma }}$ & depletion [\%] \\
\hline plasma & 61000 & 3620 & $5.9 \times 10^{-5}$ & - \\
\hline WGA affinity chromatography & & & & - \\
\hline flow-through & 58000 & 150 & - & - \\
\hline $\begin{array}{l}\text { size exclusion chromatography } \\
\text { immunoaffinity chromatography I }\end{array}$ & 2252 & 2996 & $1.3 \times 10^{-3}$ & - \\
\hline flow-through & 312 & 2690 & $8.6 \times 10^{-3}$ & 99.48 \\
\hline flow-through & 48 & 2333 & $4.9 \times 10^{-2}$ & 99.92 \\
\hline bound/eluted & 260 & 8 & - & - \\
\hline
\end{tabular}




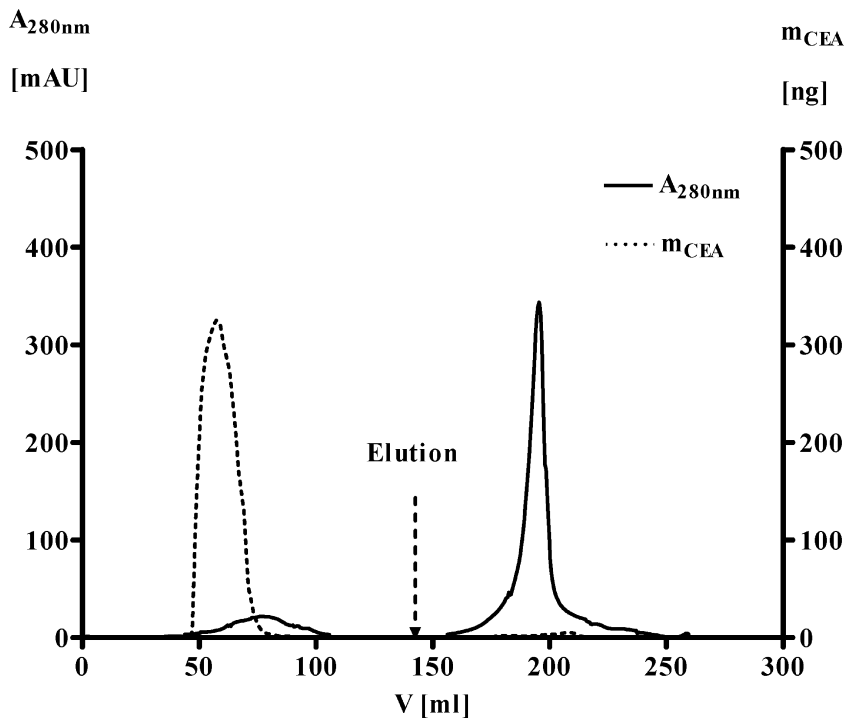

Figure 2. Elution profile of the immunoaffinity column $(60 \mathrm{~mL}$ hydrazide resin with $3 \mathrm{mg}$ llama $\mathrm{lgG} 3$ antibody $/ \mathrm{mL}$ ) loaded with the WGA bound fraction of $1 \mathrm{~mL}$ plasma spiked with 20 pMol CEA.

elution profile was determined by an ELISA (Figure 2). Finally, the sample was concentrated by binding to a second, smaller WGA lectin column, eluted with $0.5 \mathrm{M}$ GlcNAc, again desalted by gel filtration ( $50 \mathrm{mM} \mathrm{NH}_{4} \mathrm{HCO}_{3}$ ) and lyophilized. The yields obtained in the different sample preparation steps are listed in Table 2. While $99.92 \%$ of the plasma proteins were depleted by the workflow, the overall recovery of CEA was $64 \%$, thus achieving an enrichment of CEA by a factor $>800$.

The depleted sample as well as aliquots of the starting material and the WGA-bPP were adjusted to a concentration of 1 $\mu \mathrm{g} / \mu \mathrm{L}$, tryptically digested and used for $\mathrm{LC} / \mathrm{MS} / \mathrm{MS}^{\mathrm{E}}$ experiments. For each LC-MS run $500 \mathrm{ng}$ of sample were injected (details see Experimental Section). For comparison samples of the starting material (untreated plasma) and of the WGA-bPP were run in parallel. In the untreated plasma sample, 59 proteins were identified (counting only proteins found in two out of three replica runs with Protein Lynx Global Server scores $>100$ ) and in the WGA-bPP 63 proteins, out of which 26 had already been identified in the untreated plasma sample. In the immunodepleted sample 10 proteins, including the spiked CEA were identified. The results are given in Table 3. Immunodepletion drastically reduces the complexity of the sample to only a few proteins, which are not efficiently depleted by the immunoaffinity column, most prominently the $\alpha_{1}$-acid glycoproteins 1 and 2 (also named orosomucoid-1 and -2), which are strongly enriched in the WGA-bPP fraction in comparison to plasma ( $\sim 300$-fold and $\sim 200$-fold, respectively) but are immunoaffinity-depleted only by a factor of 27 and 48 respectively (corresponding to depletion rates of $96.3 \%$ and $97.9 \%$, respectively, see Table 3).

f. Analysis of Plasma from Colon Cancer Patients. Plasma samples of two colon cancer patients (each $\sim 60 \mathrm{mg}$ protein) were treated as described above for the spiked normal plasma. The results of the depletion workflow are given in Table 4 and the results of the $\mathrm{LC}-\mathrm{MS} / \mathrm{MS}^{\mathrm{E}}$ analysis in Table 5 . In addition to the plasma proteins notsufficiently depleted by the applied workflow, CEA and the plasma protease $\mathrm{C} 1$ inhibitor $^{60-62}$ were detected in both patient's samples. Determination of the plasma protease $\mathrm{Cl}$ inhibitor by an immunodiffusion assay confirmed a significantly elevated level in both samples (by $42.5 \%$ in the plasma of patient $\mathrm{A}$ and by $32.7 \%$ in the plasma of patient B) as well as in ten other plasma samples of colon cancer patients (by $51.8 \pm 32 \%$ ), possibly due to an acute-phase reaction after surgery. Plasma protease $\mathrm{Cl}$ inhibitor is a constituent of normal plasma, which was depleted in the normal control samples beyond detection. In the patient's samples however, the excess of plasma protease C1 inhibitor over the amount found in normal plasma obviously was not removed by the immunoaffinity column. This observation demonstrates that, at least for this protein, the binding capacity of the immunoaffinity column under the experimental conditions rather accurately reflects the concentration in the human plasma. Proteins found in only one of the cancer patient samples may reflect either the biological variation between individuals or, for proteins near the detection limit, the technical variance of the method.

\section{Conclusions}

Various strategies have been employed to analyze the complex proteomes of body fluids, for example, of plasma or serum. ${ }^{49}$ The complexity of these proteomes and the enormous differences in concentration pose a tremendous challenge. Obviously, the minor components cannot be analyzed with any of the presently available techniques without prior fractionation. On the other hand, any fractionation may affect the qualitative and quantitative composition of the sample. Therefore, the applied techniques have to be nondestructive to the sample and have to give high and reproducible yields. A particular attractive approach to achieve these goals is the use of affinity chromatography, either for the isolation of particular subproteomes (e.g., one of the glyco-subproteomes) or for the depletion of abundant proteins by immunoaffinity chromatography. ${ }^{50}$ In the present paper, we combine these approaches to deplete a fraction of the human glycoproteome of all normal components and thereby drastically reduce the complexity of the sample, enrich potential disease marker proteins, and significantly improve their detectability.

Lectin Affinity Fractionation. Contrary to the often applied strategy to isolate the complete glycoproteome by a combination of lectins the binding specificities of which cover all types of glycan structures, ${ }^{25,51}$ we decided to use a single lectin to pull out a small, but defined fraction of the plasma glycoproteome to achieve a substantial reduction of the complexity already in the first step. WGA was chosen, because malignant transformation of cells is often accompanied by an increase of poly- $N$-acetyllactosamine $\left((\mathrm{Gal} \beta 1-4 \quad \mathrm{GlcNAc})_{n}\right)$ on $\beta 1-6$ branched $N$-glycans chains, ${ }^{52}$ "bisecting"- $(\beta 1-4)$-GlcNAc residue, ${ }^{53}$ sialylation ${ }^{54}$ and (sialyl)-Lewis structures. ${ }^{55}$ Since these structures are specifically bound by WGA, ${ }^{16,45,46}$ the WGAbinding glyco-subproteome is a promising target for biomarker screening. However, the strategy described here can easily be modified for any other glyco-subproteome of interest or, using specific enrichment strategies, even for any other subproteome.

Immunoaffinity Depletion. The WGA binding subproteome of the human plasma isolated by the procedure described here comprises about $4 \%$ of the total protein content. The detection of minor protein components requires further depletion of abundant proteins. For this purpose we applied antibody affinity chromatography using an antibody mixture obtained by immunization of a llama with the WGA-bPP (WGA-binding plasma proteins from healthy donors). The llama heavy chain antibodies possess a higher stability ${ }^{39,40}$ in comparison to 
Table 3. Proteins Identified in a Sample of Standard Human Plasma Spiked with CEA Proteins Found Only after Immunodepletion Are Given in Bold

\begin{tabular}{|c|c|c|c|c|c|}
\hline \multirow[b]{2}{*}{$\operatorname{rank}^{a}$} & \multirow[b]{2}{*}{ identified proteins in the flow-through } & \multicolumn{3}{|c|}{ number of identified peptides ${ }^{b}$} & \multirow{2}{*}{$\begin{array}{c}c \\
\text { depletion by IAC [\%] }\end{array}$} \\
\hline & & plasma & WGA bound fraction & flow-through IAC & \\
\hline 1 & attractin & 0 & 13 & 36 & $93.1 \pm 3.3 \%$ \\
\hline 2 & $\alpha_{1}$-acid glycoprotein 1 & 6 & 7 & 13 & $96.3 \pm 0.4 \%$ \\
\hline 3 & cholinesterase & $\mathbf{0}$ & $\mathbf{0}$ & 21 & \\
\hline 4 & $\alpha_{2}$-macroglobulin & 53 & 53 & 5 & $99.9 \pm 0.1 \%$ \\
\hline 5 & $\alpha_{1}$-acid glycoprotein 2 & 6 & 6 & 10 & $97.9 \pm 0.4 \%$ \\
\hline 6 & lumican & 0 & 11 & 8 & $98.9 \pm 0.4 \%$ \\
\hline 7 & carcinoembryonic antigen (CEA) & $\mathbf{0}$ & $\mathbf{0}$ & 12 & \\
\hline 8 & L-selectin & $\mathbf{0}$ & $\mathbf{0}$ & 7 & \\
\hline 9 & corticosteroid binding globulin & $\mathbf{0}$ & $\mathbf{0}$ & 6 & \\
\hline 10 & lysosome-associated membrane glycoprotein 2 & $\mathbf{0}$ & $\mathbf{0}$ & 5 & \\
\hline
\end{tabular}

${ }^{a}$ Rank according Protein Lynx Gobal Server scores reflecting both number of identified peptides per protein and the significance of the identification. ${ }^{b}$ Peptide numbers given to demonstrate the significance of identification. ${ }^{c}$ Relative quantification derived from MS ${ }^{\mathrm{E}}$ data, all MS measurements were performed at constant protein concentration (see Methods).

Table 4. Sample Preparation of Plasma Samples from Two Colon Cancer Patients

\begin{tabular}{|c|c|c|c|c|}
\hline & protein $[\mu \mathrm{g}]$ & CEA [ng] & ratio & depletion [\%] \\
\hline plasma patient 1 & 60120 & 4690 & $7.8 \times 10^{-5}$ & - \\
\hline plasma patient 2 & 60350 & 3786 & $6.3 \times 10^{-5}$ & - \\
\hline \multicolumn{5}{|c|}{$\begin{array}{l}\text { WGA affinity chromatography } \\
\text { flow through }\end{array}$} \\
\hline patient A & 58500 & 153 & - & - \\
\hline patient B & 58000 & 198 & & \\
\hline \multicolumn{5}{|c|}{ lectin-bound fraction } \\
\hline \multicolumn{5}{|c|}{ size exclusion chromatography } \\
\hline patient $\mathrm{A}$ & 2020 & 3635 & $1.8 \times 10^{-3}$ & - \\
\hline patient B & 2126 & 2977 & $1.4 \times 10^{-3}$ & \\
\hline \multicolumn{5}{|c|}{ immunoaffinity chromatography I } \\
\hline patient A & 368 & 3135 & $8.5 \times 10^{-3}$ & 99.38 \\
\hline \multicolumn{5}{|l|}{ bound/eluted } \\
\hline \multicolumn{5}{|c|}{ immunoaffinity chromatography II } \\
\hline patient A & 60 & 2880 & $4.8 \times 10^{-2}$ & 99.90 \\
\hline patient B & 49 & 2192 & $4.5 \times 10^{-2}$ & 99.92 \\
\hline \multicolumn{5}{|l|}{ bound/eluted } \\
\hline patient A & 250 & 17 & - & - \\
\hline patient B & 262 & 12 & - & - \\
\hline
\end{tabular}

conventional antibodies and therefore are particularly suitable for the use in immunoaffinity chromatography, where the affinity resin should be reusable as often as possible. We tested the antigen binding of the various fractions of heavy chain antibodies in comparison with the fraction of conventional antibodies in the llama serum. Contrary to previous reports, ${ }^{48}$ we found no significantly different binding patterns between the conventional and the heavy-chain llama antibodies. Of the different immobilization strategies, the immobilization of the antibody at the glycosylation sites through the formation of a Schiff base to resin-bound hydrazine gave a small, but significant advantage over the immobilization at amino residues, probably because steric hindrance of antigen binding is less likely.

By immunization with the WGA bound fraction of the plasma proteins from healthy donors, we obtained in a rather straightforward way an antibody mixture directed against this particular fraction of the plasma proteins. However, one has to keep

Table 5. Proteins Identified in the Plasma of Two Colon Cancer Patients (Results for CEA Spiked Standard Plasma Given for Comparison)

\begin{tabular}{lccc}
\hline & \multicolumn{3}{c}{ number of identified peptides ${ }^{a}$} \\
\cline { 2 - 4 } \multicolumn{1}{c}{ identified protein } & $\begin{array}{c}\text { normal } \\
\text { plasma }+ \text { CEA }\end{array}$ & $\begin{array}{c}\text { plasma } \\
\text { patient A }\end{array}$ & $\begin{array}{c}\text { plasma } \\
\text { patient B }\end{array}$ \\
\hline plasma protease C1 inhibitor & 0 & 18 & 16 \\
$\alpha_{1}$-acid glycoprotein 1 & 13 & 13 & 8 \\
$\alpha_{1}$-acid glycoprotein 2 & 10 & 12 & 7 \\
lumican & 8 & 10 & 6 \\
serum albumin & 0 & 9 & 0 \\
carcinoembryonic antigen & 12 & 6 & 6 \\
attractin & 36 & 6 & 0 \\
carboxypeptidase N & 0 & 6 & 0 \\
IgA-C 1 1 region & 0 & 4 & 0 \\
$\quad{ }^{a}$ Peptide numbers given solely to demonstrate & the & significance of \\
identification. & &
\end{tabular}


in mind that the immunogenic potential of proteins can vary widely. Therefore, a considerable excess of immobilized antibody over antigen had to be applied to bind and eliminate most of the plasma proteins. At least an 80-fold excess of immobilized llama IgG3 heavy-chain antibody over antigen was necessary to achieve an overall depletion of $\sim 98 \%$ of the WGAbound plasma protein fraction. The most abundant proteins found in the flow-through of the immunoaffinity column were the $\alpha_{1}$ - and $\alpha_{2}$-acidic glycoproteins and in addition a few other proteins listed in Table 3 . The acidic glycoproteins had already been identified in preliminary tests as proteins, which are incompletely bound by the llama antibody preparation. It is not yet clear whether the $\alpha_{1}$ - and $\alpha_{2}$-acidic glycoproteins are generally not very immunogenic or whether they contain glycoforms which are not recognized by the antibodies.

Practical Applicability. A large excess of antibody poses the threat of unspecific binding of the desired analytical targets, that is, the proteins not normally found in human plasma, by cross-reacting antibodies. Also, highly immunogenic proteins present at low concentrations in normal plasma may be removed by a large excess of antibody, even if their plasma concentration is significantly increased, thus obscuring any disease-related increase. We addressed this question by spiking the WGA-bPP with the known colon cancer biomarker carcinoembryonic antigen ${ }^{56-59}$ (CEA) at a concentration of $20 \mathrm{pM} /$ $\mathrm{mL}$. No significant loss of the CEA was detected after passing the plasma protein mixture over the immunoaffinity column (Figure 1a). This, of course, does not exclude the possibility that other, unknown marker proteins are removed by the immunoaffinity column, either due to binding to crossreacting antibodies or indirectly due to complex formation with proteins recognized by the immobilized antibodies. This, however, is a general problem associated with any enrichment procedure of unknown targets the properties of which cannot be predicted.

After we established a reliable and reproducible workflow for the isolation of a subproteome of the human plasma (in this case the WGA binding fraction) and the specific depletion of the abundant proteins found in this subproteome, we applied this procedure to plasma samples of two colon carcinoma patients. After depletion of $99.92 \%$ of the plasma proteins, we identified by $\mathrm{MS}^{\mathrm{E}}$ mass spectrometry the grossly increased levels of CEA in both samples, in addition to the proteins detected also in normal plasma due to insufficient depletion (Table 5). The detection of the plasma protease $\mathrm{Cl}$ inhibitor in both patient plasma samples (where the concentration of this protein was elevated in comparison to the normal serum) demonstrates that the binding capacity of the immunoaffinity column under the experimental conditions rather accurately reflects the concentration of the normal components of human plasma. As mentioned above, this is obviously not the case for all proteins of the WGA-binding subproteome of the plasma, as the $\alpha_{1}$-acidic glycoproteins 1 and 2 as well as attractin are not efficiently removed. Other proteins, which may be strongly immunogenic in llama, may be depleted beyond detection, even if their concentration is increased in a pathological state. However, one should keep in mind that small increases $(<2-3)$ would most probably not be useful as biomarkers, since such changes would in most cases be within the range of the normal variation between individuals. ${ }^{63}$

Comparison with Other Depletion Strategies. The comparison of the depletion strategy described here with conventional approaches is difficult. The most efficient depletion method described hitherto is a two-step procedure using immobilized avian IgY antibody columns (Seppro, GenWay Biotech, SanDiego), in the first step directed against the 12 most abundant plasma proteins (Seppro IgY12) and in the second step against 77 moderately abundant plasma proteins (Seppro SuperMix). This procedure is applied by Qian et al. ${ }^{34}$ and by Lin et al. ${ }^{31}$ In both studies, the success of the depletion procedure has been measured by the number of low-abundant proteins detected after depletion. It should be noted that our depletion strategy follows a different goal: instead of making as many low-concentrated protein as possible detectable, we try, by depleting all proteins normally contained in plasma, to bring out the differences between normal and pathologicalstate plasma more clearly. Thus, we reduce the complexity of the samples enriching potential marker proteins at the expense of all normal plasma components.

Taken together the data shown in this paper demonstrate: -Antibodies generated by immunization with a subproteome (obtained by affinty fractionation) can be used to efficiently immunodeplete most of the proteins of the particular subproteome.

-Proteins not normally contained in the subproteome are not significantly depleted by the antibodies.

-The combination of affinity fractionation with immunodepletion is a powerful strategy for the detection of low abundant, disease-associated proteins in human body fluids. The tools described here can be applied to any disease state, in which the composition of the plasma proteome deviates from the normal state. In addition to single biomarkers, patterns of biomarkers may be established, which allow one to discern disease states more precisely than presently possible.

Abbreviations: CEA, carcinoembryonic antigen; DTT, dithiothreitol; GlcNAc, $N$-acetyl-glucosamine; IAC, immunoaffinity chromatography; SEC, size exclusion chromatography; UPLC, ultra performance liquid chromatography; WGA, wheat germ agglutinin; WGA-bPP, WGA-binding plasma proteins.

Supporting Information Available: Tables of the yields of llama antibody fractionation, yields of antibody immobilization on different resins, binding capacity of antibody affinity colums. Western blot assay of the antigen specificity of the llama IgG subtypes. This material is available free of charge via the Internet at http://pubs.acs.org.

\section{References}

(1) Hanash, S.; Pitteri, S.; Faca, V. Mining the plasma proteome for cancer biomarkers. Nature 2008, 452 (7187), 571-9.

(2) Orntoft, T.; Vestergaard, E. Clinical aspects of altered glycosylation of glycoproteins in cancer. Electrophoresis 1999, 20 (2), 362-71.

(3) Ludwig, J.; Weinstein, J. Biomarkers in cancer staging, prognosis and treatment selection. Nat. Rev. Cancer 2005, 5 (11), 845-56.

(4) Anderson, N.; Anderson, N. The human plasma proteome: history, character, and diagnostic prospects. Mol. Cell. Proteomics 2002, 1 (11), 845-67.

(5) Anderson, N.; Polanski, M.; Pieper, R.; Gatlin, T.; Tirumalai, R.; Conrads, T.; Veenstra, T.; Adkins, J.; Pounds, J.; Fagan, R.; Lobley, A. The human plasma proteome: a nonredundant list developed by combination of four separate sources. Mol. Cell. Proteomics 2004, 3 (4), 311-26.

(6) Villar-Garea, A.; Griese, M.; Imhof, A. Biomarker discovery from body fluids using mass spectrometry. J. Chromatogr., B: Anal. Technol. Biomed. Life Sci. 2007, 849 (1-2), 105-14.

(7) Omenn, G.; States, D.; Adamski, M.; Blackwell, T.; Menon, R.; Hermjakob, H.; Apweiler, R.; Haab, B.; Simpson, R.; Eddes, J.; Kapp, E.; Moritz, R.; Chan, D.; Rai, A.; Admon, A.; Aebersold, R.; Eng, J.; Hancock, W.; Hefta, S.; Meyer, H.; Paik, Y.; Yoo, J.; Ping, P.; Pounds, J.; Adkins, J.; Qian, X.; Wang, R.; Wasinger, V.; Wu, C.; Zhao, X.; Zeng, R.; Archakov, A.; Tsugita, A.; Beer, I.; Pandey, A.; Pisano, M.; Andrews, P.; Tammen, H.; Speicher, D.; Hanash, S. Overview of 
the HUPO Plasma Proteome Project: results from the pilot phase with 35 collaborating laboratories and multiple analytical groups, generating a core dataset of 3020 proteins and a publicly-available database. Proteomics 2005, 5 (13), 3226-45.

(8) Tuck, M.; Chan, D.; Chia, D.; Godwin, A.; Grizzle, W.; Krueger, K.; Rom, W.; Sanda, M.; Sorbara, L.; Stass, S.; Wang, W.; Brenner, D. Standard operating procedures for serum and plasma collection: early detection research network consensus statement standard operating procedure integration working group. J. Proteome Res. 2009, 8 (1), 113-7.

(9) Ostroff, R.; Foreman, T.; Keeney, T.; Stratford, S.; Walker, J.; Zichi, D. The stability of the circulating human proteome to variations in sample collection and handling procedures measured with an aptamer-based proteomics array. J. Proteomics 2010, 73 (3), 64966.

(10) Hortin, G.; Sviridov, D. The dynamic range problem in the analysis of the plasma proteome. J. Proteomics 2010, 73 (3), 629-36.

(11) Whiteaker, J.; Zhang, H.; Eng, J.; Fang, R.; Piening, B.; Feng, L.; Lorentzen, T.; Schoenherr, R.; Keane, J.; Holzman, T.; Fitzgibbon, M.; Lin, C.; Cooke, K.; Liu, T.; Camp, D. n.; Anderson, L.; Watts, J.; Smith, R.; McIntosh, M.; Paulovich, A. Head-to-head comparison of serum fractionation techniques. J. Proteome Res. 2007, 6 (2), 828-36.

(12) Faca, V.; Pitteri, S.; Newcomb, L.; Glukhova, V.; Phanstiel, D.; Krasnoselsky, A.; Zhang, Q.; Struthers, J.; Wang, H.; Eng, J.; Fitzgibbon, M.; McIntosh, M.; Hanash, S. Contribution of protein fractionation to depth of analysis of the serum and plasma proteomes. J. Proteome Res. 2007, 6 (9), 3558-65.

(13) de Godoy, L.; Olsen, J.; de Souza, G.; Li, G.; Mortensen, P.; Mann, M. Status of complete proteome analysis by mass spectrometry: SILAC labeled yeast as a model system. Genome Biol. 2006, 7 (6), R50.

(14) Bodzon-Kulakowska, A.; Bierczynska-Krzysik, A.; Dylag, T.; Drabik, A.; Suder, P.; Noga, M.; Jarzebinska, J.; Silberring, J. Methods for samples preparation in proteomic research. J. Chromatogr., B: Anal. Technol. Biomed. Life Sci. 2007, 849 (1-2), 1-31.

(15) Macek, B.; Mann, M.; Olsen, J. Global and site-specific quantitative phosphoproteomics: principles and applications. Annu. Rev. Pharmacol. Toxicol. 2009, 49, 199-221.

(16) Yang, Z.; Hancock, W. Approach to the comprehensive analysis of glycoproteins isolated from human serum using a multi-lectin affinity column. J. Chromatogr., A 2004, 1053 (1-2), 79-88.

(17) Qiu, R.; Regnier, F. Use of multidimensional lectin affinity chromatography in differential glycoproteomics. Anal. Chem. 2005, 77 (9), 2802-9.

(18) Shimizu, K.; Katoh, H.; Yamashita, F.; Tanaka, M.; Tanikawa, K.; Taketa, K.; Satomura, S.; Matsuura, S. Comparison of carbohydrate structures of serum alpha-fetoprotein by sequential glycosidase digestion and lectin affinity electrophoresis. Clin. Chim. Acta 1996, 254 (1), 23-40.

(19) Okuyama, N.; Ide, Y.; Nakano, M.; Nakagawa, T.; Yamanaka, K.; Moriwaki, K.; Murata, K.; Ohigashi, H.; Yokoyama, S.; Eguchi, H.; Ishikawa, O.; Ito, T.; Kato, M.; Kasahara, A.; Kawano, S.; Gu, J.; Taniguchi, N.; Miyoshi, E. Fucosylated haptoglobin is a novel marker for pancreatic cancer: a detailed analysis of the oligosaccharide structure and a possible mechanism for fucosylation. Int. J. Cancer 2006, 118 (11), 2803-8.

(20) Thompson, S.; Kelly, C.; Griffiths, I.; Turner, G. Abnormallyfucosylated serum haptoglobins in patients with inflammatory joint disease. Clin. Chim. Acta 1989, 184 (3), 251-8.

(21) Thompson, S.; Guthrie, D.; Turner, G. Fucosylated forms of alpha1 -antitrypsin that predict unresponsiveness to chemotherapy in ovarian cancer. Br. J. Cancer 1988, 58 (5), 589-93.

(22) Brockhausen, I. Mucin-type O-glycans in human colon and breast cancer: glycodynamics and functions. EMBO Rep. 2006, 7 (6), 599604.

(23) Prakash, S.; Robbins, P. Glycotyping of prostate specific antigen. Glycobiology 2000, 10 (2), 173-6.

(24) Ohyama, C.; Hosono, M.; Nitta, K.; Oh-eda, M.; Yoshikawa, K.; Habuchi, T.; Arai, Y.; Fukuda, M. Carbohydrate structure and differential binding of prostate specific antigen to Maackia amurensis lectin between prostate cancer and benign prostate hypertrophy. Glycobiology 2004, 14 (8), 671-9.

(25) Plavina, T.; Wakshull, E.; Hancock, W.; Hincapie, M. Combination of abundant protein depletion and multi-lectin affinity chromatography (M-LAC) for plasma protein biomarker discovery. $J$. Proteome Res. 2007, 6 (2), 662-71.

(26) Yang, Z.; Hancock, W.; Chew, T.; Bonilla, L. A study of glycoproteins in human serum and plasma reference standards (HUPO) using multilectin affinity chromatography coupled with RPLC-MS/MS. Proteomics 2005, 5 (13), 3353-66.
(27) Zhang, H.; Liu, A.; Loriaux, P.; Wollscheid, B.; Zhou, Y.; Watts, J.; Aebersold, R. Mass spectrometric detection of tissue proteins in plasma. Mol. Cell. Proteomics 2007, 6 (1), 64-71.

(28) Li, C.; Simeone, D.; Brenner, D.; Anderson, M.; Shedden, K.; Ruffin, M.; Lubman, D. Pancreatic cancer serum detection using a lectin/ glyco-antibody array method. J. Proteome Res. 2009, 8 (2), 48392.

(29) Jung, K.; Cho, W.; Regnier, F. Glycoproteomics of plasma based on narrow selectivity lectin affinity chromatography. J. Proteome Res. 2009, 8 (2), 643-50.

(30) Zhang, L.; Lu, H.; Yang, P. Specific enrichment methods for glycoproteome research. Anal. Bioanal. Chem. 2010, 396 (1), 199203.

(31) Lin, B.; White, J. T.; Wu, J.; Lele, S.; Old, L. J.; Hood, L.; Odunsi, K. Deep depletion of abundant serum proteins reveals low-abundant proteins as potential biomarkers for human ovarian cancer. Proteomics Clin. Appl. 2009, 3 (7), 853-61.

(32) Dardé, V.; Barderas, M.; Vivanco, F. Depletion of high-abundance proteins in plasma by immunoaffinity subtraction for twodimensional difference gel electrophoresis analysis. Methods Mol. Biol. 2007, 357, 351-64.

(33) Echan, L.; Tang, H.; Ali-Khan, N.; Lee, K.; Speicher, D. Depletion of multiple high-abundance proteins improves protein profiling capacities of human serum and plasma. Proteomics 2005, 5 (13), 3292-303.

(34) Qian, W.; Kaleta, D.; Petritis, B.; Jiang, H.; Liu, T.; Zhang, X.; Mottaz, H.; Varnum, S.; Camp, D. n.; Huang, L.; Fang, X.; Zhang, W.; Smith, R. Enhanced detection of low abundance human plasma proteins using a tandem IgY12-SuperMix immunoaffinity separation strategy. Mol. Cell. Proteomics 2008, 7 (10), 1963-73.

(35) Pernemalm, M.; Lewensohn, R.; Lehtiö, J. Affinity prefractionation for MS-based plasma proteomics. Proteomics 2009, 9 (6), 1420-7.

(36) Muyldermans, S.; Cambillau, C.; Wyns, L. Recognition of antigens by single-domain antibody fragments: the superfluous luxury of paired domains. Trends Biochem. Sci. 2001, 26 (4), 230-5.

(37) Muyldermans, S.; Lauwereys, M. Unique single-domain antigen binding fragments derived from naturally occurring camel heavychain antibodies. J. Mol. Recognit. 1999, 12 (2), 131-40.

(38) Arbabi Ghahroudi, M.; Desmyter, A.; Wyns, L.; Hamers, R.; Muyldermans, S. Selection and identification of single domain antibody fragments from camel heavy-chain antibodies. FEBS Lett. 1997, 414 (3), 521-6.

(39) van der Linden, R.; Frenken, L.; de Geus, B.; Harmsen, M.; Ruuls, R.; Stok, W.; de Ron, L.; Wilson, S.; Davis, P.; Verrips, C. Comparison of physical chemical properties of llama VHH antibody fragments and mouse monoclonal antibodies. Biochim. Biophys. Acta 1999, 1431 (1), 37-46.

(40) Pérez, J.; Renisio, J.; Prompers, J.; van Platerink, C.; Cambillau, C.; Darbon, H.; Frenken, L. Thermal unfolding of a llama antibody fragment: a two-state reversible process. Biochemistry 2001, 40 (1), 74-83.

(41) Silva, J.; Denny, R.; Dorschel, C.; Gorenstein, M.; Kass, I.; Li, G.; McKenna, T.; Nold, M.; Richardson, K.; Young, P.; Geromanos, S. Quantitative proteomic analysis by accurate mass retention time pairs. Anal. Chem. 2005, 77 (7), 2187-200.

(42) Bateman, K.; Castro-Perez, J.; Wrona, M.; Shockcor, J.; Yu, K.; Oballa, R.; Nicoll-Griffith, D. MSE with mass defect filtering for in vitro and in vivo metabolite identification. Rapid Commun. Mass Spectrom. 2007, 21 (9), 1485-96.

(43) Hamers-Casterman, C.; Atarhouch, T.; Muyldermans, S.; Robinson, G.; Hamers, C.; Songa, E.; Bendahman, N.; Hamers, R. Naturally occurring antibodies devoid of light chains. Nature 1993, 363 (6428), 446-8.

(44) Wagener, C.; Clark, B.; Rickard, K.; Shively, J. Monoclonal antibodies for carcinoembryonic antigen and related antigens as a model system: determination of affinities and specificities of monoclonal antibodies by using biotin-labeled antibodies and avidin as precipitating agent in a solution phase immunoassay. J. Immunol. 1983, 130 (5), 2302-7.

(45) Gallagher, J.; Morris, A.; Dexter, T. Identification of two binding sites for wheat-germ agglutinin on polylactosamine-type oligosaccharides. Biochem. J. 1985, 231 (1), 115-22.

(46) Allen, A.; Neuberger, A.; Sharon, N. The purification, composition and specificity of wheat-germ agglutinin. Biochem. J. 1973, 131 (1), 155-62.

(47) Debray, H.; Decout, D.; Strecker, G.; Spik, G.; Montreuil, J. Specificity of twelve lectins towards oligosaccharides and glycopeptides related to N-glycosylproteins. Eur. J. Biochem. 1981, 117 (1), 41-55.

(48) van der Linden, R.; de Geus, B.; Stok, W.; Bos, W.; van Wassenaar, D.; Verrips, T.; Frenken, L. Induction of immune responses and 
molecular cloning of the heavy chain antibody repertoire of Lama glama. J. Immunol. Methods 2000, 240 (1-2), 185-95.

(49) Qian, W.; Jacobs, J.; Liu, T.; Camp, D. n.; Smith, R. Advances and challenges in liquid chromatography-mass spectrometry-based proteomics profiling for clinical applications. Mol. Cell. Proteomics 2006, 5 (10), 1727-44.

(50) Azarkan, M.; Huet, J.; Baeyens-Volant, D.; Looze, Y.; Vandenbussche, G. Affinity chromatography: a useful tool in proteomics studies. J. Chromatogr., B: Anal. Technol. Biomed. Life Sci. 2007. 849 (1-2), 81-90.

(51) Yang, Z.; Hancock, W. Monitoring glycosylation pattern changes of glycoproteins using multi-lectin affinity chromatography. J. Chromatogr., A 2005, 1070 (1-2), 57-64.

(52) Srinivasan, N.; Bane, S.; Ahire, S.; Ingle, A.; Kalraiya, R. Poly $\mathrm{N}$-acetyllactosamine substitutions on $\mathrm{N}$ - and not O-oligosaccharides or Thomsen-Friedenreich antigen facilitate lung specific metastasis of melanoma cells via galectin-3. Glycoconj. J. 2009, 26 (4), 445-56.

(53) Gu, J.; Taniguchi, N. Potential of N-glycan in cell adhesion and migration as either a positive or negative regulator. Cell Adh. Migr. 2008, 2 (4), 243-5.

(54) Wang, F.; Cui, S.; Sun, L.; Qu, X.; Xie, Y.; Zhou, L.; Mu, Y.; Tang, W.; Wang, Y. High expression of alpha 2, 3-linked sialic acid residues is associated with the metastatic potential of human gastric cancer. Cancer Detect. Prev. 2009, 32 (5-6), 437-43.

(55) Yuan, K.; Kucik, D.; Singh, R.; Listinsky, C.; Listinsky, J.; Siegal, G. Alterations in human breast cancer adhesion-motility in response to changes in cell surface glycoproteins displaying alpha-L-fucose moieties. Int. J. Oncol. 2008, 32 (4), 797-807.
(56) Wagener, C.; Hain, F.; Födisch, H.; Breuer, H. Localisation of carcinoembryonic antigen in embryonic and fetal human tissues. Histochemistry 1983, 78 (1), 1-9.

(57) Leusch, H.; Drzeniek, Z.; Hefta, S.; Markos-Pusztai, Z.; Wagener, C. The putative role of members of the CEA-gene family (CEA, NCA an BGP) as ligands for the bacterial colonization of different human epithelial tissues. Zentralbl. Bakteriol. 1991275, (1), 11822.

(58) Wagener, C.; Hain, F.; Breuer, H.; Olude, S.; Cremer, H.; MüllerWallraf, R. Immunohistochemical demonstration of carcinoembryonic antigen in normal, transitional and inflamed colonic mucosa. Oncodev. Biol. Med. 1981, 2 (5), 331-43.

(59) Metze, D.; Grunert, F.; Neumaier, M.; Bhardwaj, R.; Amann, U.; Wagener, C.; Luger, T. Neoplasms with sweat gland differentiation express various glycoproteins of the carcinoembryonic antigen (CEA) family. J. Cutan Pathol. 1996, 23 (1), 1-11.

(60) Kirschfink, M.; Nürnberger, W. C1 inhibitor in anti-inflammatory therapy: from animal experiment to clinical application. Mol. Immunol. 1999, 36 (4-5), 225-32.

(61) Cai, S.; Dole, V.; Bergmeier, W.; Scafidi, J.; Feng, H.; Wagner, D.; Davis, A. r. A direct role for $\mathrm{C} 1$ inhibitor in regulation of leukocyte adhesion. J. Immunol. 2005, 174 (10), 6462-6.

(62) Davis, A. r.; Cai, S.; Liu, D. C1 inhibitor: biologic activities that are independent of protease inhibition. Immunobiology 2007, $212(4-5), 313-23$.

(63) Meyer, H.; Stühler, K. High-performance proteomics as a tool in biomarker discovery. Proteomics 2007, 7, 18-26.

PR100224Y 